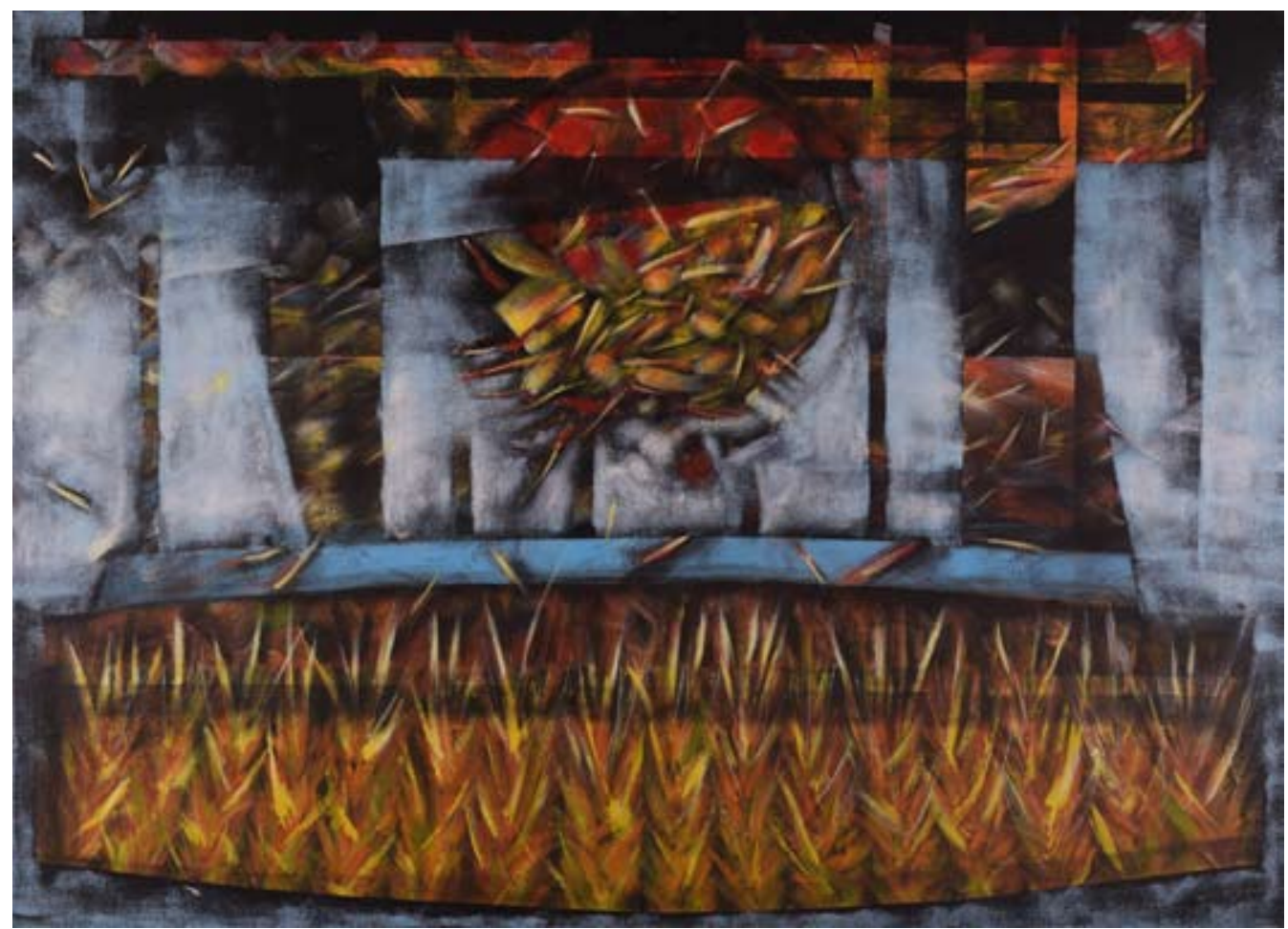

“Ferma x Gaggero (4)”, óleo sobre bastidor de fibrofácil. Gustavo Gaggero 


\title{
Acerca de las prácticas en la formación
}

\author{
Maria Graciela DI FRANCO
}

$\mathrm{A}$ ndrea Alliaud plantea en "Los artesanos de la enseñanza. Acerca de la formación de maestros con oficio" (2017) un trabajo de indagación, de pensamiento y de reflexión sobre problemáticas acuciantes del sistema educativo y en especial de la formación de futuros docentes. El texto invita, de la mano Philip Jackson, Philippe Meirieu, Francois Dubet, Daniel Pennac y George Steiner, a analizar el oficio de enseñar, tanto como producción intervención, transformación. Fuente especial de inspiración lo constituye la obra $E l$ artesano de Richard Sennett (2009) la cual le permite avanzar en cuestiones que venía trabajando en relación a la formación: a la idea de la artesanía como la habilidad de hacer las cosas bien, a la producción artesanal como la inseparable relación mano y cabeza, teoría y práctica y la potencialidad del pensar y la acción como superación de la monotonía de cualquier trabajo.

Este abordaje le resulta fructífero para abordar la enseñanza y la formación dando forma a "una obra pedagógica artesanal" (2017, p. 16) en la que aborda a las instituciones escolares en esta etapa de modernidad para poder analizar lo que implica enseñar en ellas; recupera el carácter de oficio de la enseñanza vinculado a lo que se sabe hacer y lo que nos une a los otros. En este contexto analiza los problemas políticos y pedagógicos de la formación para centrarse en las prácticas de formación, tanto de lo que se transmite y las formas apropiadas para hacerlo, como aprender de la experiencia personal y de otros para convertirse en artesanos de nuestro quehacer.
Al plantearse los desafíos de la formación docente hoy y la vieja discusión entre la teoría y la práctica vislumbra una tercera vía, la de los saberes de oficio.

No alcanza el saber disciplinar, el qué y cómo, también se necesita el para qué y por qué, la reflexión y comprensión de las dimensiones sociopolíticas, histórico-culturales, pedagógicas, metodológicas, disciplinarias, éticas, epistemológicas. De este modo los planes de estudio se complejizan, intensifican las cargas horarias, la cantidad de disciplinas, los abordajes. A la intensificación de la formación y didáctica de las disciplinas, le sucede la intensificación de la formación en la práctica mudando su histórica ubicación al final de la formación. Se trata de que se incorporen desde el inicio de la formación. No obstante "las prácticas profesionales suelen concebirse como espacios destinados al hacer, mientras que los otros espacios curriculares de la formación -al estructurarse casi exclusivamente a partir de conocimientos formalizados- se conciben como espacios destinados al saber" (Allaud, 2017, p.67). En ese sentido la práctica no descansa enteramente en los saberes profesionales formalizados sino que hay otros, estratégicos, prácticos, difíciles de formalizar, que se ponen en juego en la práctica de oficio.

En nuestra propia Facultad de Ciencias Humanas -desde el año 2009- comenzamos a preguntarnos por esa formación y el lugar del Campo de la Práctica, las cuales están “orientadas al aprendizaje sistemático de las capacidades para la actuación docente en las aulas $y$ en los distintos ámbitos donde se desempeñe profesionalmente" (Resolución No 228-CS- 
2009). Estos aprendizajes se llevan adelante en contextos y escenarios educativos reales.

Dos argumentos son centrales en esta formación que recupera el valor formativo de la práctica como actividad socialmente situada y situada en contexto socioeducativo, allí donde al decir de Alliaud, se pone en juego la práctica de oficio.

La actividad situada implica siempre cambios en el conocimiento y en la acción, ideas centrales para lo que entendemos por aprendizaje. Es decir que al analizar la participación de las personas en la acción práctica de la escuela, fundamentalmente están analizando la participación en el aprendizaje. Como diría Jean Lave (1996, p. 18), no existe un aprendizaje suis generis, sino sólo una cambiante participación en los ambientes culturalmente determinados de la vida cotidiana, y en ese caso la participación en la vida escolar sería como un cambiante proceso de comprensión en la práctica. Aquí se entiende al aprendizaje como actividad situada, heterogénea, de carácter abierto, indisociable con la actividad y con los contextos de desempeño, que tiene como eje a la comprensión como un proceso parcial y de final abierto (Lave, 1996). En este sentido, un rasgo esencial es que comenzamos a pensar respecto de la invención de nuevos conocimientos en la práctica (Engestrom, 1987).

Para Schön (1992) lo que caracteriza a los docentes como profesionales es el pensamiento práctico que éste activa cuando se enfrenta a los problemas complejos de su tarea. En un proceso de reflexión que es nítidamente social ya que, esos pensamientos de las/os profesoras/ es -tanto sus conocimientos explícitos como sus creencias- se construyen en un contexto social e histórico y son parte de esa cultura.

Trabajamos a diario para recuperar los saberes de oficio, el pensamiento práctico que permite recuperar las palabras del maestro

"Así fue como aprendí a buscar siempre y siempre el auxilio de la teoría con la cual pudiera tener mañana mejor práctica. Así fue también como nunca dicotomicé teoría de práctica, jamás las percibí aisladas una de otras, pero sí en permanente relación contradictoria, procesual”. Freire, 2007:122

Las/os autores de este volumen nos ayudan a valorar esa formación en contexto que fortalece la potencia del sentido profesional.
Víctor Figueroa Farfán y Eduardo Cavieres Fernández -Universidad Andrés Bello sede Viña del Mar y Centro de Estudios Avanzados, Universidad de Playa Ancha de Valparaísonos acercan La contribución de las movilizaciones estudiantiles a la formación ciudadana y democrática de los estudiantes secundarios chilenos

María Inés Barilá y Andrés Amoroso de la Universidad Nacional del Comahue nos acompañan con Prácticas de participación política. Experiencias de socialización de jóvenes en la 'nocturna'.

Francisco Ramallo y Luis Porta (UNMdP -CONICET) ofrecen Narrativas y trayectorias invisibilizadas. La memoria escolar y los estudiantes del Colegio Nacional de Mar del Plata

De la Universidad Autónoma de Yucatán, México Carmita Díaz López y María de Lourdes Pinto Loría plantean Vulnerabilidad educativa: Un estudio desde el paradigma socio crítico.

Cecilia Evangelina Meléndez y José Alberto Yuni (Universidad Nacional de Catamarca -CONICET) escriben La puesta en acto de las políticas socioeducativas de inclusión en escuelas secundarias de la Provincia de Catamarca, Argentina

En Reencuentro recuperamos Escuela y cultura de confluencia, obra de nuestro maestro Juan Ricardo Nervi.

\section{Bibliografía}

Alliaud A. (2017) Los artesanos de la enseñanza. Acerca de la formación de maestros con oficio. Buenos Aires: Paidos

Freire, P. (2007) La educación en la ciudad. México: Siglo XXI

Lave, J Y S. Chaiklin. (2001). Estudiar las prácticas. Buenos Aires: Editorial Amorrourtu

Schon, D. (1992) La formación de profesionales reflexivos: hacia un nuevo diseño de la enseñanza y el aprendizaje de las profesiones. Barcelona: Paidós.

Sennett, R. (2009) El artesano. Barcelona: Anagrama 